\title{
Cooperação: uma alavanca no processo de ensino-aprendizagem na educação a distância
}

*Silvana Corbellini - silvanacorbellini@gmail.com

\begin{abstract}
Resumo: O presente artigo reflete a partir de uma prática docente em educação a distância sobre a necessidade de incorporar o conceito de cooperação na área da educação a distância. Este trabalho parte da questão-problema de como o docente pode incorporar a cooperação na educação a distância? Dentro desta perspectiva, este estudo objetiva investigar como a cooperação pode ser incrementada nos ambientes virtuais de aprendizagem e quais as implicações para esta prática. A autora traça um panorama geral da teoria piagetiana e especificamente sobre a cooperação nesta teoria, estabelecendo um paralelo com a prática vivenciada e destacando a importância de se trabalhar de forma cooperativa nos ambientes virtuais de aprendizagem. Através destes estudos, salienta a importância de se fomentar trabalhos em grupos e espaços propícios para que a cooperação faça parte do cotidiano desta práxis. Considera que a cooperação é uma alavanca no processo de ensino-aprendizagem, promovendo novos sujeitos, mais ativos frente à construção do seu conhecimento.
\end{abstract}

Palavras chave: Educação a Distância; Piaget; Cooperação

\begin{abstract}
This paper argues based on a teaching practice of distance educationon the need to incorporate the concept of cooperation in distance education. This work starts by the problem-question of how teachers might incorporatecooperation in distance education? Within this perspective, this study aims toinvestigate how cooperation can be enhanced in virtual learning environmentsand the implications for this practice. The author gives an overview of Piaget's theory and specifically on cooperation in this theory, establishing a parallel withthe experienced practice and emphasizing the importance of working in a cooperative way in virtual learning environments. Through these studies, highlights the importance of encouraging group works and propitious spaces so that cooperation be part of the daily practice. Considers that cooperation is a lever in the process of teaching and learning, promoting new subjects, the most active for knowledge construction.
\end{abstract}

Keywords: Distance Education; Piaget; Cooperation

Psicóloga, Psicanalista, Mestre em Psicologia Clínica/PUCRS, Profa. do Curso de Pedagogia Modalidade a Distância PEAD/UFRGS, Tutora UFRGS. 


\section{Apresentação}

Ao colocar como título do trabalho "Cooperação: uma alavanca no processo de ensino-aprendizagem na educação a distância" abre-se um universo de possibilidades que podemos começar a problematizar. O que é cooperar? Como se aprende? Qual a relação que existe entre os conceitos de cooperar e aprender? Qual a importância da cooperação no processo de ensino-aprendizagem? Como o docente pode incrementar a cooperação nos ambientes virtuais de aprendizagem e quais as implicações para a prática do docente online?

Esta temática parte de uma reflexão sobre o percurso na prática docente presencial e também, virtual, que é o foco deste trabalho, onde cada vez mais percebemos a importância da cooperação como um mecanismo fundamental no processo de ensino-aprendizagem. Principalmente, na educação a distância, observa-se a carência existente de espaços cooperativos nos ambientes virtuais de aprendizagem. A própria questão da distância física, acaba de certa forma, sendo perpetuada nos ambientes virtuais de aprendizagem e o que se percebe, na prática, é que os alunos, muito pouco se comunicam entre si. Os debates quando são feitos, geralmente tem o docente e/ou tutor como mediadores, ou como "detentores do saber". Desta maneira, refletindo a partir da prática e da teoria piagetiana, começou-se a incrementar espaços cooperativos, bem como, relações de cooperação entre os atores do processo ensinoaprendizagem. Esta idéia foi corroborada em outros trabalhos publicados pela autora (2011, 2008), sendo que um dos pontos fundamentais que os perpassaram foi a estimulação da cooperação nos ambientes virtuais de aprendizagem e as suas consequiências positivas para os atores envolvidos no processo. Ao nos apropriarmos do conceito de cooperação e o trazermos para a prática virtual, observamos o surgimento de um novo aluno, mais comprometido, mais responsável e mais cooperativo.

Além disto, muito se debate sobre as tecnologias na área da educação. Um dos pontos para refletirmos é como estas podem vir a acrescentar à área, modificando concepções cronificadas sobre a gênese do conhecimento. Pode-se pensar que estas tecnologias contribuam neste sentido, servindo como meios para promoções de interações, diversidades de saberes, instantaneidade dos mesmos, acesso as pesquisas, entre outros. Acreditamos que sim, elas podem vir a serem ferramentas capazes de construir novas formas de educar e aprender, mas, compete aos docentes, buscar aprimoramentos e aprender a utilizar-se delas, estimulando os discentes a adquirirem também outra postura neste processo, lembrando que em Piaget o desenvolvimento social e moral também são construídos.

Para tanto, partimos da teoria piagetiana para buscarmos um entendimento do papel da cooperação, como um importante mecanismo, dentro do contexto do desenvolvimento individual.

\section{A teoria piagetiana}

A epistemologia genética concebe a construção do conhecimento na ação do sujeito. Esta teoria, desenvolvida por Jean Piaget, tinha o objetivo de buscar novos entendimentos sobre como o sujeito aprendia, uma vez que as teorias existentes até então, não respondiam de forma suficiente as perguntas formuladas sobre esta questão.

Desta forma, Piaget ao construir a sua teoria, distanciou-se do que havia até então, principalmente em relação ao Behaviorismo, que era a escola tradicional vigente na época (e ainda hoje, sumamente atuante). Interessante lembrar, que Piaget partiu dos 
erros das crianças estudadas, para constituir a gênese do conhecimento. Piaget ao formular a sua teoria rompe com o pragmatismo de um sujeito passivo, e coloca o sujeito como ativo frente ao seu processo de aprendizagem. Esta primeira concepção, já tem como fundamento implicar o sujeito em seu processo, pois, se ele não somente absorve conhecimentos, mas sim, os constrói, de uma forma prática, atuando/interagindo com os objetos, é necessário que ele modifique a sua postura, bem como o docente.

Piaget (2002) também refere que a aprendizagem não é uma atividade individual e que o conhecimento ocorre na ação. As operações mentais, conforme Piaget, são ações de uma forma interiorizada e coordenada com outras ações do mesmo tipo. Salienta que essas operações necessitam da colaboração e do intercâmbio entre os indivíduos.

Desta maneira, Piaget (2002) traz à tona a importância dos trabalhos em grupos, as pesquisas, o estímulo a autonomia do discente, sendo que as relações necessitam se alicerçar em respeito mútuo, reciprocidade e cooperação.

Aponta que a cooperação é uma ferramenta indispensável para a elaboração racional, defendendo o trabalho em grupo nas práticas educacionais como parte do processo ativo do aprendente. Cumpre salientar que com isto, Piaget não elimina a diferenciação dos pontos de vista, isto é, não se trata de homogeneizar, mas sim de colocá-los em reciprocidade.

Para Piaget (1973), quando há uma relação sujeito-objeto, onde o sujeito é um "nós" e o objeto são outros sujeitos, a interação ocorre de maneira que o conhecimento: não parte do sujeito, nem do objeto, mas sim, da interação entre eles. Desta forma, Piaget refere que os fatos mentais são paralelos aos fatos sociais, sendo que o $\mathrm{eu}$, substitui-se pelo nós e as ações e operações, transformam-se em interações, ou em outras palavras, formas de cooperação.

"A formação da lógica na criança, primeiramente, evidencia dois fatos essenciais: que as operações lógicas procedem da ação e que a passagem da ação irreversível às operações reversíveis se acompanha necessariamente de uma socialização das ações, procedendo ela mesma do egocentrismo à cooperação.” (Piaget, 1973: 96).

\section{Tics e a Educação a distância}

Tecnologia da informação e comunicação (TIC) pode ser conceituada como um conjunto de recursos tecnológicos, utilizados de forma integrada organizadas em torno de um objetivo comum, neste caso, a educação a distância.

A EaD é uma modalidade de ensino que possui características específicas. Nesta, o processo de ensino-aprendizagem não se realiza em um espaço físico compartilhado por docentes e discentes. É mediado por materiais tecnológicos e as estruturas do curso são especialmente concebidas para este fim.

A utilização das tecnologias ligadas à área da educação trouxe uma revolução nos paradigmas vigentes. Ela apresenta várias possibilidades para integrar conhecimentos e pessoas, mas para tanto, é necessário uma construção que seja realizada de forma coletiva, e para isto, requer que o seu uso seja feito com novas formas de interação.

Conforme Behar (2009), a educação atual vive um momento de transformação, e os paradigmas vigentes na sociedade não são suficientes para dar conta das relações, necessidades e desafios sociais. Refere que o modelo educativo de hoje privilegia o ensino tecnicista, que tem por objetivo preparar os sujeitos para o desempenho de papéis 
específicos, sendo que através desta prática, os discentes têm dificuldades de relacionar o conteúdo estudado com a realidade, não se sentindo instigados a investigar um tema.

Essa modalidade de ensino-aprendizagem, organizada em forma de comunidades virtuais visa incorporar várias formas de expressão, interesses, conhecimentos. Conforme Lévy (1999) uma comunidade virtual é formada a partir das afinidades de interesses, de conhecimentos, de projetos mútuos e de valores de trocas que são estabelecidos em processo de cooperação. $\mathrm{O}$ autor também salienta que essas relações online, não são relações em que as emoções estão excluídas. Aponta que elas também se manifestam no ciberespaço, tanto no aspecto cooperativo, como no conflitivo.

Estas relações virtuais acabam tendo a necessidade de criar regras, leis, normas, como qualquer relação presencial, para tanto, podemos citar a existência do "Netiqueta", que é um código que norteia as relações virtuais. Se ocorreu o surgimento deste, aponta para a existência de conflitos e da necessidade de um mediador que norteasse essas relações. Regras, normas, sempre existiram como uma forma de conduzir uma boa convivência entre os seres humanos e sem estas não existiria a civilização. No cotidiano, depende de cada um de nós o cumprimento das mesmas, o respeito ao próximo, visando o estabelecimento de relações saudáveis e harmoniosas. Assim também o é, no mundo virtual. As regras de boa convivência, de educação também são necessárias no mundo virtual, pois independentemente das ferramentas, são pessoas que estão ali. A palavra netiqueta, decorre da fusão de duas palavras inglesas: "net" (rede) e "etiqueta" (conjunto de normas de conduta sociais). Este código é um conjunto de recomendações que visa evitar mal-entendidos em comunicações via internet e regrar condutas em situações específicas.

Entre os internautas estas várias "regras" valem, mesmo que muitas vezes, elas não se encontrem explícitas, mas implícitas, como por exemplo, o compartilhamento de boas maneiras, as trocas de conhecimentos, a reciprocidade de auxílio entre os membros de uma mesma comunidade, os serviços de apoio em redes sociais, etc. No ciberespaço ainda há uma grande liberdade de expressão, cada um pode postar o que quiser, desde que não atinja ao outro. Desta forma, as divergentes opiniões sempre acrescem ao debate, contribuindo e, de outro lado, também podendo trazer conflitos justamente pela diversidade de pontos de vista.

Os conflitos em Piaget são "desacomodadores", desta maneira, são fontes de desenvolvimento. Através de conflitos cognitivos, que o autor coloca como sendo uma das funções do professor promovê-los, o aluno desacomoda e precisa ir à busca de novas respostas (aprender) para novamente (re)acomodar. Nas comunidades virtuais também ocorrem os conflitos e muitas vezes, eles necessitam de mediação. Assim como, constroem-se sentimentos de amizade, de cooperação, de trocas, similares as relações presenciais. Então, mesmo na comunidade virtual é necessária a presença de um docente (ou mediador) para que o objetivo comum seja mantido: a busca pelo aprender.

Neste sentido, ao pensarmos no aprender e na educação a distância, surge a questão da cooperação que é um dos pontos essenciais na teoria piagetiana e um dos alicerces do processo de ensino-aprendizagem.

Então, das interações, tanto presenciais, como as virtuais, originam-se novas estruturas cognitivas, sempre num processo contínuo. Desta forma, salientamos que as Tics, na educação a distância, devem ter como meta a mediação deste processo de ensino-aprendizagem, promovendo a mudança de estruturas, tanto cognitivas, como afetivas, ou seja, permitir que o discente modifique as suas competências e habilidades, tanto no nível cognitivo, passando de um estágio ao outro, como também afetiva e 
moralmente, passando da heteronomia para a autonomia, responsabilizando-se por este processo.

Na prática docente em $\mathrm{EaD}$, observa-se ainda um certo reducionismo do papel da educação, a uma transmissão da informação, o que levanta o temor da substituição do docente, pela máquina. Mas, este temor só é justificado através das concepções tradicionais da educação, onde o que impera é a reprodução do mesmo, ou conforme Edges, a reposição incessante do velho, mesmo mediante algumas ações mais modernas (1990).

Conforme Nevado (2001), a partir do momento em que modificamos a conceituação da aprendizagem tradicional para a de um processo social de criação permanente - uma cultura na qual cada um estará continuamente atento ao aperfeiçoamento da cooperação e do serviço mútuo, o papel da educação e dos seus atores será não só resgatado, mas valorizado. Isso significa, não a substituição do professor, mas sim, o aumento de seu poder de ação, abrindo-se espaços para que aprenda maneiras criativas de fazer e de interagir com os outros.

Para que realmente, as tecnologias possam contribuir de uma forma eficaz, nessas modificações que se pretendem, necessita-se que haja uma mudança na postura dos atores envolvidos. Se o docente, continuar na mesma posição, na mesma concepção epistemológica e utilizar-se das Tics como "máquinas de ensinar", o aluno continuará na mesma posição também e responderá as perguntas de acordo com as respostas esperadas. Outra maneira é de o docente usar as Tics como ferramentas pedagógicas, visando estimular ao aprendente a busca por novas soluções, criando um ambiente rico, com espaços nos quais ele possa se manifestar, trocar com os colegas, questionar, cooperar, atuando e construindo o seu próprio conhecimento.

\section{A cooperação na teoria piagetiana}

Neste sentido, ao pensarmos no aprender e na educação a distância, surge a questão da cooperação que é um dos pontos essenciais na teoria piagetiana e um dos alicerces do processo de ensino-aprendizagem.

"Cooperar na ação é operar em comum, isto é, ajustar por meio de novas operações (qualitativas ou métricas) de correspondência, reciprocidade ou complementaridade, as ações executadas por cada um dos parceiros" (Piaget, 1973, p.105).

Importante fazer uma distinção com o termo colaborar, que comumente, vemos sendo utilizados como sinônimos, mas que para Piaget são conceitos distintos. Colaborar é a união de ações que são realizadas de forma isolada pelos componentes de um grupo, mesmo que tenham um objetivo comum.

Desta forma, a cooperação vai além, pois se encontra vinculada à interação, requerendo vínculos e reciprocidade afetiva entre os componentes do processo ensinoaprendizagem. Estas interações possibilitam a mudança do aprendente em sua estrutura e a do grupo como um todo, como um novo sistema de interações. O acréscimo de vários pontos de vista de forma integrativa modifica toda a estrutura, tanto em nível individual, como grupal.

A cooperação fundamenta-se justamente, na coordenação destes diversos pontos de vista, pelas operações de correspondência, reciprocidade ou complementaridade e pela existência de regras autônomas de condutas baseadas no respeito mútuo. Para tanto, é necessário que os componentes do grupo possuam um sistema comum de convenções, tornando-se uma base para outras reconstruções, podendo ocorrer trocas cooperativas, bem como operações recíprocas. Desta forma, Piaget (1973) aponta que 
são necessárias algumas condições para que exista uma real cooperação, sendo elas: existência de uma escala comum de valores, conservação dessa escala e reciprocidade na interação. Salienta que estas três condições de equilíbrio só ocorrem na cooperação e que as suas condições não se viabilizam nas relações em que se apresentem o egocentrismo ou a coação.

Desta maneira, podemos colocar que a cooperação requer uma descentração em relação ao egocentrismo intelectual e moral, bem como uma liberação em relação às coações sociais que este egocentrismo mantém. Quando falamos em autonomia, opomos a heteronomia, uma das evoluções da moralidade apontadas por Piaget, instalando-se com isto no sujeito, a auto-disciplina. Assim, esta implica em uma cooperação baseada em um sistema de normas, em que cada qual seja responsável pela manutenção do mesmo.

Como diz Piaget:

"É onde a cooperação implica um sistema de normas, diferindo da suposta livre troca cuja liberdade se torna ilusória pela ausência de tais normas. E é porque a verdadeira cooperação é tão frágil e tão rara no estado social dividido entre os interesses e as submissões, assim como a razão permanece tão frágil e tão rara em relação às ilusões subjetivas e ao peso das tradições." (Piaget, 1973, p. 111).

É uma missão difícil sem dúvida, de instaurarmos um nível cooperativo nas relações, pois para tanto, temos que partir da premissa de que os aprendentes e mesmo os docentes, tenham alcançado o nível de autonomia que torne possível as trocas cooperativas. Mas, o que pudemos perceber ao longo de nossa prática e de nossas pesquisas, é do quanto realmente é um "processo", contínuo e permanente, em que sim, o docente tem uma função primordial e digamos inclusive, vital, de estimular, auxiliar ao aprendente em suas construções, tanto em nível cognitivo, como nos afetivo e moral.

A cooperação refere-se a um tipo de interação em que é necessário que os valores trocados estejam em equilíbrio, em que não haja opressão, coerção, abuso do outro. A cooperação é um acordo (explícito ou implícito) entre as partes, de uma forma clara e em que todos ganhem. Para Piaget a cooperação é o melhor caminho para o desenvolvimento da autonomia intelectual e moral.

A educação não pode ser vista de uma forma dicotômica, pois ela é um todo, e não temos como pensar em sujeitos aprendentes, pensantes, criativos, autônomos em um domínio cognitivo, se ele não o for também no aspecto moral. Se o docente impõe ao aprendente o seu saber, o qual o mesmo deve absorver/incorporar, e submeter-se a esta coerção, funcionando ainda de forma heterônoma, o saber que ele irá constituir será o do docente e não o seu próprio, isto é, será uma "reprodução" e não uma construção de conhecimento. Em outras palavras, se o aprendente é passivo intelectualmente, também o será moralmente. Ou, nas palavras de Piaget:

"Neste sentido as relações pedagógicas só podem supor um clima de confiança, no qual a afetividade está compreendida. Na realidade a educação forma um todo indissociável e não é possível formar personalidades autônomas no domínio moral se, por outro lado, o indivíduo está submetido a uma coerção intelectual tal que deva se limitar a aprender passivamente, sem tentar descobrir por si mesmo a verdade: se ele é passivo intelectualmente não pode ser livre moralmente. Mas 
reciprocamente, se sua moral consiste exclusivamente numa submissão à vontade adulta e se as únicas relações sociais que constituem a vida da classe escolar são as que ligam cada aluno individualmente a um mestre que determina todos os poderes, ele não pode tampouco ser ativo intelectualmente. (PIAGET, 1973 apud DOLLE, 1987, p. 198).

A tomada de consciência do pensamento próprio é estimulada pela cooperação, pois esta pressupõe a autonomia dos sujeitos. O sujeito ao descentrar-se do seu egocentrismo, abre novas perspectivas para si mesmo ao confrontar-se com outros pensamentos, enquanto que, ao ficar preso ao "si mesmo", enclausura-se no seu delírio, acreditando-se ser o "dono da verdade" por não se permitir questionar e modificar o seu ponto de vista.

A cooperação no sentido piagetiano pode ser considerada como possibilitadora de atos criativos, pois permite que os sujeitos se impliquem de uma forma autônoma na construção, modificando-se a partir das interações, dialogando, trocando uns com os outros e desta forma acrescentando novos saberes. O trabalho em grupo, como salientado na obra de Piaget, serve como um plus para os aprendentes, pois no confronto de idéias, numa atividade de confiança, ele pode fazer fluir os pensamentos, estimulando a criação. Para tanto, urge que estes espaços existam, se constituam nos ambientes virtuais de aprendizagem e que os docentes estimulem os seus alunos a serem sujeitos ativos.

Lembrando também, que a utilização das tecnologias no processo de ensinoaprendizagem dos alunos não garante por si só, que esses venham realmente a aprender. Essas ferramentas devem servir para a construção da aprendizagem dos alunos e para tanto, necessita de um docente competente, capaz que domine não somente a tecnologia, mas também a pedagogia, sabendo valer-se da mesma, como uma ferramenta para o desenvolvimento integral de seu aluno.

Desta forma, as ferramentas que os ambientes virtuais de aprendizagem disponibilizam, podem ser usadas pelos docentes de várias maneiras, estimulando o trabalho individual, ou o grupal. As mesmas ferramentas podem ser utilizadas de diversas formas, tanto os fóruns, quanto os chats (que são interativas), como mesmo os blogs, banco de dados, wikis, podem ser configurados de forma que os discentes se apropriem como espaços de construção coletiva, trocando entre eles, através de mensagens, de envios de textos, de colaboração com os escritos dos colegas, com pedidos de ajuda sobre suas próprias questões, compartilhamento de pesquisas, etc.

O que queremos salientar é que a cooperação necessita, antes de qualquer coisa, um espaço, seja "físico" ou "virtual" para que ela ocorra. Se o ambiente virtual de aprendizagem for configurado de uma forma tal em que não haja possibilidades de trocas, não há como construir conhecimento, nem como auxiliar ao aluno no seu desenvolvimento integral. Assim como, se o docente perpetuar o ensino tradicional, de nada adiantará toda a tecnologia criada. O docente estará se utilizando das Tics para perpetuar a educação tradicional. Como dizem, "apenas roupagem nova, para velhos corpos..."

$\mathrm{Na}$ educação também ocorre a necessidade constante de atualização por parte dos docentes, e isto, não somente na área do seu conhecimento específico, mas também na pedagógica. Com as mudanças de concepções epistemológicas vigentes até a pouco tempo, o docente também tinha uma posição digamos que, bastante cômoda, onde ele era o "detentor do saber" e o discente era quem "absorvia o saber". Estes métodos tradicionais ainda são presentes em nossas instituições de ensino; mas uma mudança 
tem se desenhado ao longo do tempo e quando falamos de educação a distância, esta mudança é salientada pela novidade que a própria $\mathrm{EaD}$ já traz em seu bojo. Com isto, não queremos dizer que na prática da Educação a Distância, não exista o ensino tradicional, mas sim, salientar que a questão da educação a distância já traz imbricada novos modelos, questionamentos, indagações que impõem uma diferença.

Compete esclarecer, que não queremos dizer que não haja docentes que se utilizem das Tics como se utilizavam do "quadro negro", ou seja, apenas mudam as ferramentas, o espaço, mas o ensino continua o mesmo. Mas, de qualquer maneira, elas trazem contribuições cada vez maiores, em que o docente vê-se obrigado a mudar de posição, pois ele não tem primeiramente, como manter-se na posição de "detentor do saber", pois o saber está posto, está a disposição de todos, ao alcance de um teclar. As tecnologias possuem, sem dúvida, um importante papel na educação, mas ela é responsável pela infra-estrutura, e sem a "mão humana", ela não promove alteração.

É essencial que os docentes aprendam a utilizar-se das tecnologias e as aliem as práticas pedagógicas, o que exigirá mais do que modificações nas práticas docentes, e sim, um exercício de um novo paradigma que faz com que o professor deixe de ser o único detentor do conhecimento, evidenciando o seu papel de estimulador da construção cooperativa de conhecimento.

Assim, a utilização das novas tecnologias como ferramentas, traz uma grande contribuição para a prática do ensino-aprendizagem em todos os níveis de ensino. $\mathrm{O}$ importante é que esta utilização traz várias possibilidades que poderão ser efetuadas de acordo com a concepção epistemológica que sustenta a prática docente. Destacamos a necessidade de que estas utilizações sejam acompanhadas de reflexões sobre as modificações que implicam e avaliações das melhores alternativas de incorporá-las à nossa prática cotidiana.

“(...) A prática pedagógica nesta modalidade deve proporcionar momentos de reflexão e problematização das situações pedagógicas vividas, o que implica um exercício de crítica sobre sua atuação e sobre a atuação do outro nos espaços, tempos e contextos em que estão interagindo, pois, além do conteúdo que está sendo trabalhado, há a dimensão pedagógica, a qual precisa ser pensada e vivida de forma reflexiva." (HENRIQUES, C. M. et all, 2008).

O docente, cada vez mais necessita estar atento as novas tecnologias, as novas práticas pedagógicas, aos novos conhecimentos, ao novo sujeito / discente que emerge e ser flexível frente às novas demandas que se impõem. Hoje, o docente é muito mais um mediador do processo de ensino-aprendizagem e a sua função é a de auxiliar, mostrar o caminho, possibilitando que o aprendente construa o seu conhecimento. Esta tese é de Piaget, que parte do pressuposto de que o conhecimento é o resultado da relação do sujeito com o seu meio, da ação do sujeito sobre o objeto, que promovem desacomodações e novas acomodações, num constante ir e vir na construção de seu conhecimento.

\section{Considerações Finais}

Concluímos este breve estudo, no sentido de refletirmos sobre a cooperação como uma alavanca no processo de ensino-aprendizagem, estabelecendo pontos que consideramos fundamentais neste processo: as novas tecnologias, as práticas pedagógicas, o papel do docente, como um mediador deste processo, construindo novas 
relações com os seus alunos (tanto presenciais, como virtuais), onde as relações cooperativas tenham um papel de destaque no planejamento pedagógico e não sejam acessórios.

Conforme Piaget:

“... na vida social, como na vida individual, o pensamento procede da ação e uma sociedade é essencialmente um sistema de atividades, cujas interações elementares, no sentido próprio, em ações se modificando umas às outras, segundo certas leis de organização ou equilíbrio. (Piaget, 1973:33).

"O conhecimento humano é essencialmente coletivo, e a vida social constitui um dos fatores essenciais da formação e do crescimento dos conhecimentos.(Piaget 1973:17).

O docente atual tem uma função sumamente importante, como estimulador e propiciador de espaços cooperativos em salas de aulas, utilizando-se das tecnologias como ferramentas e não como fins em si mesmos, para que valores como cooperação, ética, cidadania sejam transmitidos.

Implantar a tecnologia é uma tarefa relativamente simples, a mudança do processo de ensino-aprendizagem é a tarefa mais complexa. Para alcançarmos as modificações que pretendemos, torna-se necessário alicerçar os atores que integram este contexto, em especial, aos docentes, propiciando que estes primeiramente, passem a ser agentes provocadores das mudanças necessárias a nossa sociedade.

Então, podemos corroborar esta ideia colocando que as tecnologias podem servir para o aprimoramento e para as modificações que se fazem necessárias no contexto da educação. Mas, também, não podemos ficar numa posição passiva e não avaliarmos os novos desafios que se impõem a partir dela, como a própria formação do docente, que implica hoje em, além de dar conta de sua área específica de conhecimento, o domínio das tics e de reflexões sobre a sua prática pedagógica.

Salientamos que a criação de espaços (fóruns, chats, blogs, wikis, banco de dados, etc) e os estímulos, bem como o uso adequado, condizente com uma prática pedagógica, que permitam que a cooperação possa ser uma das ferramentas no processo da educação, torna-se essencial, fomentando novos sujeitos, criativos e produtores do seu próprio conhecimento.

Na sociedade atual, globalizada, a demanda é por sujeitos que trabalhem de uma forma inovadora e para tanto a educação tem uma função primordial: de formar sujeitos ativos, capazes de construírem o seu conhecimento. Neste cenário, o docente da EaD, precisa estar atento, reconstruindo a sua própria práxis, atuando como mediador pedagógico, contribuindo para a formação integral do aprendente.

Para finalizar, podemos citar uma reflexão, que foi atribuída a George Bernard Shaw (mesmo que de uma autoria incerta):

"Se você tiver uma maçã e eu tiver uma maçã, e trocarmos as maçãs, então cada um continuará uma maçã. Mas, se você tiver uma idéia e eu tiver uma idéia, e trocarmos estas idéias, então cada um de nós terá duas idéias."

E, apenas acrescentamos a partir da citação, que cada um de nós terá duas ideias que se multiplicarão em novas ideias a partir de uma prática cooperativa. 


\section{Referências}

ARAGON DE NEVADO, R. Espaços interativos de construção de possíveis: uma nova modalidade de formação de professores. Tese de Doutorado. PGIE/UFRGS, 2001. BEHAR, P.; MACEDO, A.; AMARAL, C.; ALBA, C.; SCHNEIDER, D.; LONGHI,M.; BERCHT, M.; BERNARDI, M. BECKER, M.; NOTARE, M.; WALQUIL, M.; LEITE, S.; MORESCO, S.; FROZI, A. (Org.). Modelos pedagógicos em educação a distância. Porto Alegre: Artmed, 2009.

CORBELLINI, S.; CORTE REAL, Luciane Magalhães. Trabalho de conclusão de curso (TCC) em um curso de graduação modalidade EAD: uma proposta cooperativa construída em ambiente a distância. RENOTE. Revista Novas Tecnologias na Educação, v. 9, p. 17-27, 2011.

CORBELlini, S.; CORTE REAL, Luciane Magalhães. Proposta Cooperativa em Curso de Graduação a Distância Construída em Wikis. In: LACLO 2011 - Sexta Conferência Latinoamericana de Objetos de Aprendizagem y Tecnologias de La Educacion. Uruguai: Montevideu, 2011.

CORBEllini, S.; CORTE REAL, Luciane Magalhães. Proposta de uso de Wiki como Arquitetura Pedagógica: cooperação. In: XXII Simpósio Brasileiro de Informática na Educação e XVII Workshop de Informática na Escola (SBIE e WIE, 2011).

CORBELLINI, S.; CORTE REAL, Luciane Magalhães. Café \& Cia: uma proposta de espaço de interações informais em EAD. In: XXVIII Congresso da Sociedade Brasileira de Computação, 2008, Belém do Pará. Anais do XXVIII Congresso da Sociedade Brasileira de Computação, 2008, p. 406-409.

DOLLE, Jean Marie. Para compreender Jean Piaget: uma iniciação à psicologia genética piagetiana. Rio de Janeiro: Guanabara Koogan S.A., 1987.

ETGES, Norberto J. A escola e a produção do arcaico. In: Educação e Realidade. Porto Alegre (15): 22-28. Jan/jun 1990.

GUIA INTERNET. Disponível: http://www.icmc.usp.br/manuals/BigDummy/ Acesso em: 04.10.2011.

HENRIQUES, Cecília Machado; AIMI, Daniela da Silva; GIORDANI, Estela Maris; FELDKERCHER, Nadiane. Implicações dos profissionais envolvidos nas práticas pedagógicas em educação a distância. Revista Paidéi@, UNIMES VIRTUAL, Volume 1, número 2, dez.2008. Disponível em: http://revistapaideia.unimesvirtual.com.br. Acesso em: 22/09/2011.

LEVY, Pierre. Cibercultura. Rio de Janeiro: Editora 34, 1999.

MONTAGERO e MAURICE-NAVILLE. Piaget ou a inteligência em evolução. Porto Alegre: Artes Médicas, 1998.

PIAGET, Jean. Sobre a pedagogia. São Paulo: Casa do Psicólogo, 1998.

PIAGET, Jean. Estudos sociológicos. São Paulo: Companhia Editora Forense, 1973.

PIAGET, Jean. O julgamento moral na criança. São Paulo: Editora Mestre Jou, 1977. PIAGET, Jean. Para onde vai a educação? 16 ed. Rio de Janeiro: José Olympio, 2002. 